\title{
CLAY MINERAL FRACTIONS STUDIED BY MÖSSBAUER SPECTROSCOPY AND CONVENTIONAL METHODS
}

\author{
K. Punakivi, T. Ericsson and R. Wäppling
}

\begin{abstract}
K. Punakivi, T. Ericsson and R. Wäppling 1975: Clay mineral fractions studied by Mössbauer spectroscopy and conventional methods. Bull. Geol.
\end{abstract} Soc. Finland 47, 171-174.

\begin{abstract}
A X-ray, wet-chemical and thermal study of different fractions of a clay sample has been combined with a Mössbauer spectroscopic investigation. It is shown that conventional wet-chemical analysis can give ferric-ferrous ratios that are very much higher than those obtained from a Mössbauer analysis. The need for a systematic Mössbauer study of well characterized standard clay minerals and the possibilities to use Mössbauer spectroscopy to study the weathering of minerals is stressed.

K. Punakivi, Geological Survey of Finland, SF-02150 Espoo 15, Finland.

T. Ericsson, R. Wäppling, Institute of Physics, University of Uppsala, S-751 21

Uppsala 1, Sweden.
\end{abstract}

\section{Introduction}

In the study of clay minerals it is customary to look upon the distribution of grain sizes in the material. The type of clay is investigated using primarily $\mathrm{X}$-ray diffraction and sometimes thermal analysis to obtain the mineral content and the composition is obtained from chemical analysis. Information on the weathering of the primary minerals can be obtained e.g. from the ferric-ferrous ratio change with grain size for iron-bearing minerals. The use of Mössbauer spectroscopy to establish the ferric-ferrous ratio has proved to have some advantages in mineralogical studies (Bancroft 1973) and in the present paper this relatively new method is applied also to clay minerals.

\section{Experimental details}

The material used is a glacial clay taken about $3 \mathrm{~km}$ west of the finnish town Borgå. The clay has sedimented under sweet-water conditions and was taken from a depth of $1.2 \mathrm{~m}$ (altitude $16.5 \mathrm{~m}$ over the present sea level). The bedrock in this area is granite, partly migmatitic. The clay sample was separated into four fractions by sedimentation, the particel size distribution being made by the hydrometer method (Elonen 1971). Every fraction was analysed using $\mathrm{X}$-ray diffractometry on oriented slides (Bradley 1953). The Philips PW-1010/PW-1050 X-ray diffraction setup of the Geological Survey of Finland was used with Ni-filtered $\mathrm{Cu}$-radiation. The chemical composition of the fractions and the unseparated 

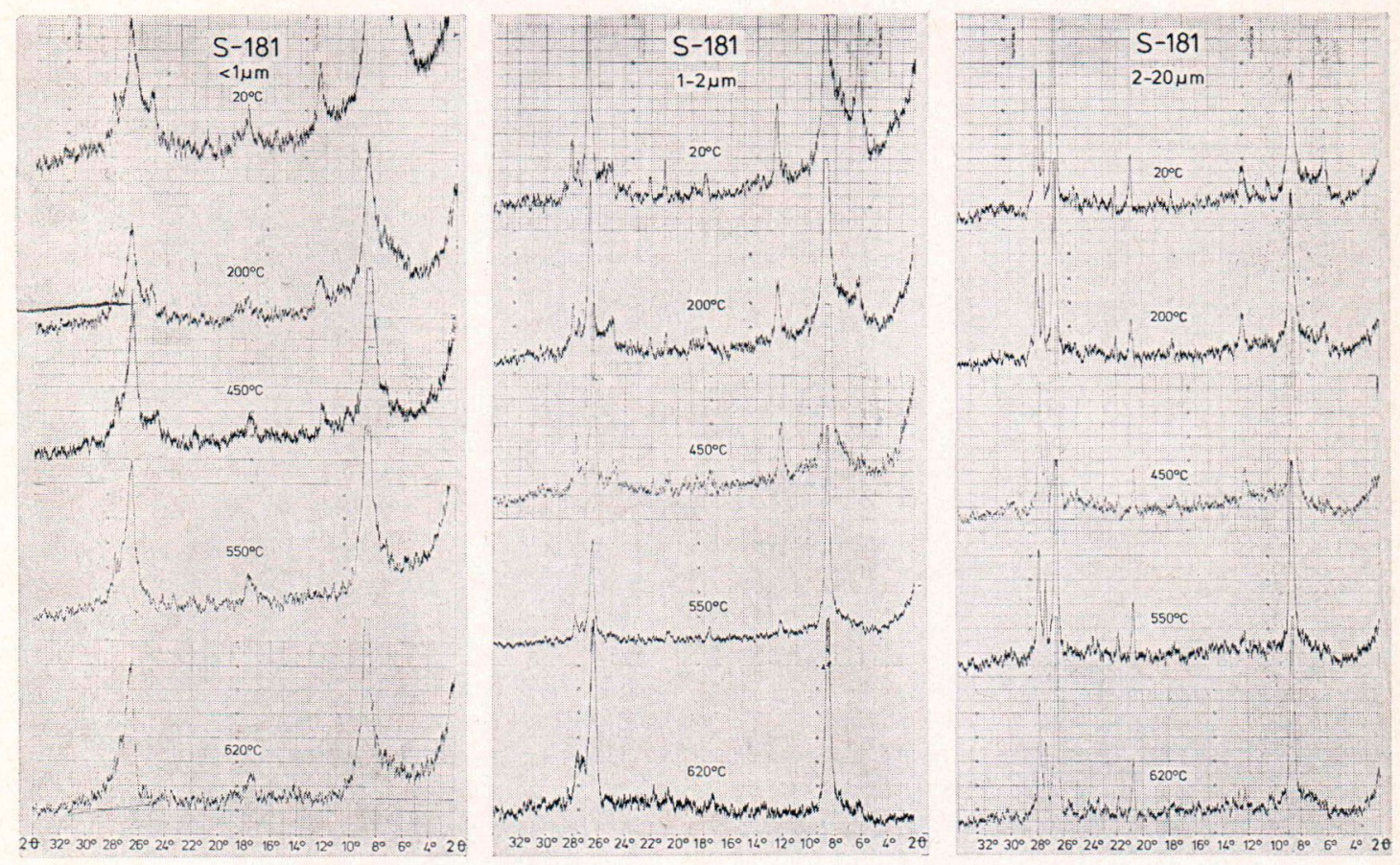

Fig. 1. X-ray diffraction patterns for three of the clay fractions recorded at different temperatures.

clay was estimated from conventional wetchemical analysis. Differential thermal (DTA) and thermogravimetric (TG) analysis was also performed in order to give additional information on the types of clay minerals involved.

Absorbers suitable for Mössbauer spectroscopy was made by pressing thin discs, containing about $3 \mathrm{mg} / \mathrm{cm}^{2}$ of natural iron, from a mixture of the actual fraction and boron nitride powder. Room temperature spectra were recorded on a constant acceleration spectrometer (Wäppling 1967) using a ${ }^{57} \mathrm{Co} R h$ source.

\section{Results}

The X-ray diffraction patterns, at different temperatures, are shown in Fig. 1. From the positions of the diffraction maxima one can deduce the main constituents of the clay mineral to be, irrespective of grain size, dioctahedral illite, chlorite and some vermiculite. This is further supported by the temperature variation of the diffraction patterns. Since d(001) for vermiculite shows a strong decrease on going from room temperature to $200{ }^{\circ} \mathrm{C}$, due to loss of water of hydration (Brown 1961), the reduction in peak intensity at $2 \theta \sim 6^{\circ}$ has this origin. The peak at $2 \theta \sim 12^{\circ}$ decreases in intensity above $450{ }^{\circ} \mathrm{C}$ and is indicative of the decomposition of chlorite. The results of the thermal measurements are in conformity with the conclusions drawn from the X-ray diffraction results.

The results of the chemical analysis is given in Table 1. Due to lack of material, all the fractions could unfortunately not be analysed. From the table it is seen that a larger ferricferrous ratio is found for smaller grain sizes. It also seems that the total amount of iron increases for smaller grain sizes. An increasing iron contents with decreasing grain size has also been reported earlier (Sippola 1974). This can, at 
TABLE 1.

The result of the chemical analysis for three fractions of the clay.

\begin{tabular}{|c|c|c|c|}
\hline Comp. & $<1 \mu \mathrm{m}$ & $2-20 \mu \mathrm{m}$ & unsep. \\
\hline $\mathrm{SiO}_{2} \ldots \ldots \ldots \ldots$ & 47.83 & 67.38 & 62.98 \\
\hline $\mathrm{TiO}_{2} \ldots \ldots \ldots \ldots$ & 1.04 & 0.67 & 0.71 \\
\hline $\mathrm{Al}_{2} \mathrm{O}_{3} \ldots \ldots \ldots \ldots$ & 19.55 & 14.22 & 15.36 \\
\hline $\mathrm{Fe}_{2} \mathrm{O}_{3} \ldots \ldots \ldots \ldots$ & 8.73 & 2.62 & 4.86 \\
\hline $\mathrm{FeO} \ldots \ldots \ldots \ldots$ & 2.23 & 1.46 & 1.38 \\
\hline $\mathrm{MnO} \ldots \ldots$ & 0.10 & 0.07 & 0.08 \\
\hline $\mathrm{MgO} \ldots \ldots$. & 4.10 & 1.61 & 2.18 \\
\hline $\mathrm{CaO} \ldots \ldots \ldots \ldots$ & 1.39 & 2.41 & 1.90 \\
\hline $\mathrm{Na}_{2} \mathrm{O} \ldots \ldots \ldots \ldots$ & 1.32 & 2.86 & 2.16 \\
\hline $\mathrm{K}_{2} \mathrm{O} \ldots \ldots \ldots \ldots$ & 3.76 & 3.28 & 3.17 \\
\hline $\mathrm{P}_{2} \mathrm{O}_{5} \ldots \ldots \ldots \ldots$ & 0.14 & 019 & 0.16 \\
\hline $\mathrm{H}_{2} \mathrm{O}+\ldots \ldots \ldots \ldots$ & 5.70 & 1.89 & 3.21 \\
\hline \multirow[t]{2}{*}{$\mathrm{H}_{2} \mathrm{O}-\ldots \ldots \ldots \ldots$} & 3.50 & 0.40 & 1.69 \\
\hline & 99.30 & 99.06 & 99.84 \\
\hline
\end{tabular}

least partly, be explained by the presence of $\mathrm{SiO}_{2}$ in larger grains as is also born out by the chemical analysis.

Room temperature Mössbauer spectra for three of the fractions and for the unfractionated material are shown in Fig. 2. To the measured data points Lorentzian lines have been least squares fitted using the Uppsala University IBM $370 / 55$ computer. The spectrum of the $<1 \mu \mathrm{m}$ fraction can be fitted to only four lines corresponding to ferric and ferrous ions, both types showing electric quadrupole splittings. For the larger grains the presence of minor impurities is evident from Fig. 2. The amplitudes of the dominating lines in the spectra are, however, not seriously affected and a fitting involving more than two quadrupole doublets have therefore not been attempted. The values obtained for the Mössbauer parameters are summarized in Table 2.

\section{TABLE 2.}

The values obtained for the Mössbauer parameters for different clay fractions. The isomer shift, $\delta$, is relative natural iron at room temperature. $\triangle \mathrm{E}$ is defined as ${ }^{1} /{ }_{2} \mathrm{e}^{2} \mathrm{qQ}\left(1+\eta^{2} / 3\right)^{0.5}, \quad \eta$ is the asymmetry parameter.

\begin{tabular}{|c|c|c|c|c|c|}
\hline \multirow{2}{*}{\multicolumn{2}{|c|}{ Grain size }} & \multicolumn{2}{|c|}{$\mathrm{Fe}^{2}+$} & \multicolumn{2}{|c|}{$\mathrm{Fe}^{3+}$} \\
\hline & & $\delta$ & $\Delta \mathrm{E}$ & $\delta$ & $\Delta \mathrm{E}$ \\
\hline$<1 \mu \mathrm{m}$ & $\ldots$ & 1.01 & 2.28 & 0.33 & 0.57 \\
\hline $2-20 \mu \mathrm{m}$ & $\ldots \ldots$ & 1.01 & 2.30 & 0.33 & 0.70 \\
\hline$>20 \mu \mathrm{m}$ & $\ldots \ldots \ldots$ & 1.01 & 2.30 & 0.31 & 0.72 \\
\hline unsep. . . & & 1.00 & 2.30 & 0.34 & 0.60 \\
\hline
\end{tabular}

(1) MY

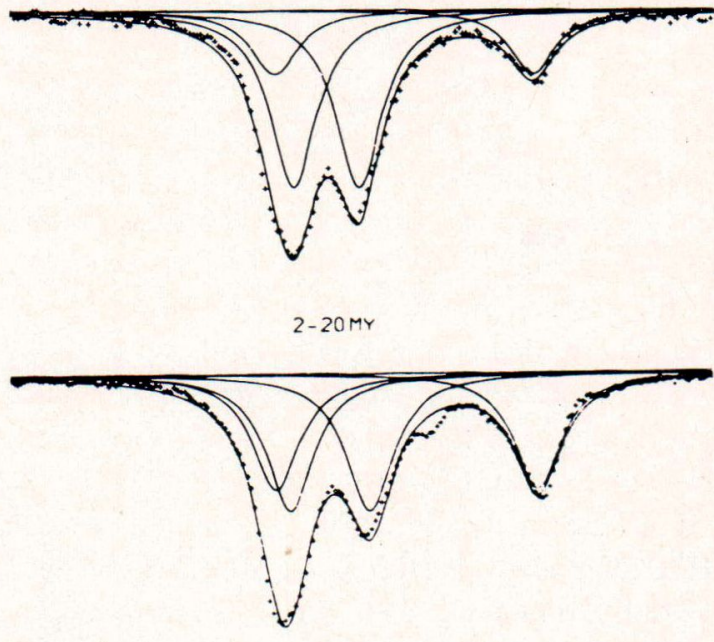

, $20 \mathrm{MY}$
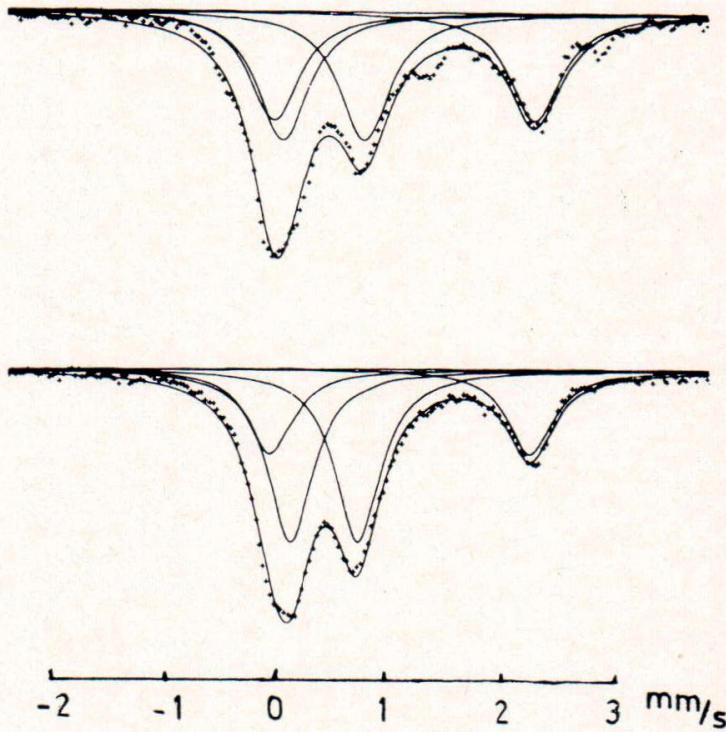

Fig. 2. Mössbauer spectra for different fractions of the clay recorded at room temperature. The lowest spectrum is for the unseparated clay.

\section{Discussion}

There are very few Mössbauer spectroscopic investigations of clay minerals. The parameters for illite have been given by Weaver et al. (1967) and Malathi et al. (1969). In the latter publication 
only two absorption lines were reported while in the first paper an additional absorption, interpreted as due to ferrous iron, was found. The reported isomer shifts are for $\mathrm{Fe}^{3+} \sim 0.35 \mathrm{~mm} / \mathrm{s}$ and for $\mathrm{Fe}^{2}+\sim 1.1 \mathrm{~mm} / \mathrm{s}$ and the corresponding quadrupole splittings are $\sim 0.6 \mathrm{~mm} / \mathrm{s}$ and $\sim 2$ $\mathrm{mm} / \mathrm{s}$. As concerns chlorite an isomer shift of $0.95 \mathrm{~mm} / \mathrm{s}$ and a quadrupole splitting of $2.5 \mathrm{~mm} / \mathrm{s}$ are also given by Weaver et al. The spectra obtained in these rather early studies are of a poor quality and the discrepancies between the above values and the values in Table 2 are therefore not to be taken too seriously.

It is evident that in order to make possible a Mössbauer analysis of the constituents in clay minerals a number of well characterized standard materials have to be investigated. Such studies are in progress. For the moment it is sufficient to say that the results found are in agreement with what is to be expected from a mica.

The ferric-ferrous ratios as obtained from the wet chemical analysis and from the relative areas of the ferric and ferrous doublets in the Mössbauer spectra are given in Table 3 . The identification of the ferric viz. the ferrous doublet in a Mössbauer spectrum is rather straightforward since the isomer shifts as well as the quadrupole splittings differ markedly. It is clear from the table that the conventional chemical analysis gives ferric-ferrous ratios that lie substantially above the results of the non-destructive Mössbauer method. In comparing intensities in Mössbauer spectra one has to be careful so that

\section{TABle 3.}

Comparison between ferric-ferrous ratios obtained from wet-chemical analysis and from the relative areas of the ferric and ferrous doublets in the Mössbauer spectra.

\begin{tabular}{c|c|c}
\hline \multirow{2}{*}{ Grain size } & Chem anal. & Möss. spect. \\
\cline { 2 - 3 } & $\mathrm{Fe}^{3+} / \mathrm{Fe}^{2+}$ & $\mathrm{Fe}^{3+} / \mathrm{Fe}^{2+}$ \\
\hline $1 \mu \mathrm{m} \ldots \ldots \ldots \ldots$ & 3.52 & 2.78 \\
$2-20 \mu \mathrm{m} \quad \ldots \ldots \ldots \ldots$ & 1.61 & 1.19 \\
$>20 \mu \mathrm{m} \quad \ldots \ldots \ldots \ldots$ & $-\overline{1}$ & 1.19 \\
unsep. $\ldots \ldots \ldots \ldots$ & 3.17 & 2.04
\end{tabular}

saturation effects (tending to an equalization of line intensities) are taken care of. In the present study this has been made for the $<1 \mu \mathrm{m}$ fraction by measuring at different absorber thicknesses and extrapolating to zero thickness. From this it could be deduced that the corrections to be applied to the other fractions were $\sim 2 \%$. The reason for the discrepancies with the wet chemical results are to be found in the fact that when disolving the minerals, before the analysis, a partial oxidation takes place. Mössbauer spectroscopy is thus superior in this case since it is not hampered by such uncertainties.

In conclusion, the present investigation has shown the advantages in using Mössbauer spectroscopy for the determination of ferricferrous ratios for clay minerals. Since the method also can be used as a finger-print technique in identifying the type of mineral it should be of great importance $e . g$. in the study of weathering processes. To this effect a systematic study of standard materials has to be performed in order to form a basis for future work.

\section{REFERENCES}

Bancroft, G. M. (1973) Mössbauer spectroscopy: An introduction for inorganic chemists and geochemists. McGraw-Hill, London. 252 p.

Bradley, W. F. (1953) Analysis of mixed-layer clay mineral structures. Anal. Chem. 25: 729.

Brown, G. (1961) The X-ray identification and crystal structures of clay minerals. Mineralogical Society, London. 544 p.

Elonen, P. (1971) Particle-size analysis of soil. Acta Agr. Fenn. 122. 122 p.

Malathi, N., Puri, S. P. and Saraswat, I. P. (1969)
Mössbauer studies of iron in Illite and Montmorillonite. J. Phys. Soc. Japan 26: 680.

Sippola, J. (1974) Mineral composition and its relation to texture and to some chemical properties in Finnish subsoils. Ann. Agric. Fenn. 13: 168-234.

Waewer, C. E., Wampler, J. M. and Pecuil, T. E. (1967) Mössbauer analysis of iron in clay minerals. Science 156: 204.

Wäppling, R. (1967) A versatile Mössbauer spectrometer. Ark. Fys. 33: 337.

Manuscript received, April 10, 1975. 